\title{
Functional characterization of a yellow laccase from Leucoagaricus gongylophorus
}

Priscila Tomie Leme Ike ${ }^{1}$, Ariele C. Moreira ${ }^{1}$, Fernando G. de Almeida', Douglas Ferreira' , Willian Garcia Birolli², Andre Luiz Meleiro Porto ${ }^{2}$ and Dulce Helena F. Souza ${ }^{1 *}$

\begin{abstract}
In this work we have identified, using mass spectrometry, two laccases produced by Leucoagaricus gongylophorus. One of them, Lac1 Lg, was isolated, purified and characterized. Lac1 Lg, a monomeric enzyme, was studied using ABTS and syringaldazine substrates. Lac1 Lg presented kcat/Km almost threefold higher for syringaldazine than for ABTS, showing a higher catalytic efficiency of Lac1 Lg for syringaldazine. The interference of several metal ions and substances in the laccase activity were evaluated. Lac1 Lg did not absorb at $600 \mathrm{~nm}$, which is a characteristic of so-called yellow laccases. Lac1 Lg also was able to oxidize non-phenolic substrate (anthracene) in the absence of an exogenous mediator, showing that the enzyme has potential to explore in biotechnological processes. Our Lac1 Lg three-dimensional molecular model, constructed using homology modeling, showed that the Lac1 Lg catalytic site is very closed to blue laccases.
\end{abstract}

Keywords: Yellow laccase, Leucoagaricus gongylophorus, Kinetic enzyme, Non-phenolic substrate, Molecular modeling

\section{Background}

Laccases (EC 1.10.3.2, p-diphenol:dioxygen oxidoreductase) are enzymes that can oxidize a wide spectrum of aromatic and non-aromatic compounds (Gianfreda et al. 1999) and contain copper atoms in the catalytic center being usually called multicopper oxidases (Baldrian 2006; Piontek et al. 2002). These enzymes are widely distributed in higher plants, fungi, bacteria and insects, presenting different physiological function (Riva 2006; Wu et al. 2013). Fungal laccases generally present high redox potential giving them potential for application in technological processes (Brijwani et al. 2010) such as in bioremediation of some toxic chemical wastes, as well as in the production of ethanol and food, the paper and textile industries, and organic synthesis (Viswanath et al. 2014; Thurston 1994).

Laccases have been described as containing four copper atoms, which are classified into three different types

\footnotetext{
*Correspondence: dulce@ufscar.br

1 Departamento de Química, Universidade Federal de São Carlos, São

Carlos, SP, Brazil

Full list of author information is available at the end of the article
}

(T1, T2 and T3), depending on the region where they are found in the enzyme molecule (Solomon et al. 1996). The T1 copper site is the site that binds the primary reducing substrate and T2 and T3 sites (containing copper types-2, 3 and 4), where reduction of molecular oxygen and release of water takes place. Laccases with typical UV-visible spectra (at resting state) show two maxima around 280 and $600 \mathrm{~nm}$ and one shoulder near $330 \mathrm{~nm}$ (Madhavi and Lele 2009). The maximum at $600 \mathrm{~nm}$ has been attributed to type 1 copper (T1), which is responsible for the intense blue color of the laccases, and the weak absorbance near $330 \mathrm{~nm}$ has been related to type 3 copper (T3). These copper atoms have been also classified in three groups using electron paramagnetic resonance (EPR) spectroscopy: types 1 and 2 copper (T1 and T2) are EPR detectables and type 3 copper (T3) has no EPR signal (Leontievsky et al. 1997). Although these features have been reported for most studied laccases, some laccases do not have an absorption band around $600 \mathrm{~nm}$ (showing also no EPR signal due the type 1 copper) and are called 'yellow' or 'yellow/white' laccases (Leontievsky et al. 1997). However, more recently a yellow laccase isolated from the fungus Sclerotinia sclerotiorum showed no

\section{贷 Springer}

(c) 2015 lke et al. This article is distributed under the terms of the Creative Commons Attribution 4.0 International License (http:// creativecommons.org/licenses/by/4.0/, which permits unrestricted use, distribution, and reproduction in any medium, provided you give appropriate credit to the original author(s) and the source, provide a link to the Creative Commons license, and indicate if changes were made. 
absorbance at $600 \mathrm{~nm}$ but it was detectable in the EPR spectrum making this enzyme different of others yellow laccases (Mot et al. 2012).

Typical blue laccases require the presence of small compounds (the so-called chemical mediators) to catalyze the reaction where the substrates are non-phenolic compounds (Bourbonnais and Paice 1992) but Leontievsky et al. (1997) have described that yellow laccases catalyze reactions using non-phenolic substrates without mediators. These behaviors of yellow laccases have been associated with modifications in the type 1 copper, for example, with the binding of a lignin-derived mediator in the catalytic site (Leontievsky et al. 1997). This mediator could be coming from the culture medium of which the enzyme has been isolated. However, Huang et al. (2011) described a yellow laccase obtained in a recombinant form (i.e. in a synthetic medium) and this suggests that lignin decomposition products are not required for the existence of yellow laccases. Sequence alignments of laccases have shown that there is no obvious pattern corresponding to yellow or blue laccases (Daroch et al. 2014). The latest hypothesis is that small changes in the sequences of yellow laccases can be responsible for the formation of polyproline helices and alternative folding of these enzymes (Daroch et al. 2014; Mate et al. 2013).

Leucoagaricus gongylophorus, a basidiomycete, is a fungus that lives in symbiosis with leaf-cutting ants Atta and Acromyrmex, which are considered major herbivores in the tropics (Cherret 1986). The metabolic potential of $L$. gongylophorus has been analyzed and has been demonstrated that the fungus metabolizes several different polysaccharides (Gomes de Siqueira et al. 1998; Silva et al. 2006). As part of our efforts to understand the enzymes involved in the polysaccharide metabolic process, we started the studies of the enzymes involved in this pathway (Moreira et al. 2014). Recently, the draft genome $L$. gongylophorus was sequenced (Accession: PRJNA179280) and studies have showed that this fungus produces distinct sets of lignocellulases throughout the different stages of biomass degradation, including numerous cellulases and laccases that likely play an important role in lignocellulose degradation (Aylward et al. 2013). Nine putative laccase-coding genes in the genome of L. gongylophorus have also been reported, and it was observed that laccases detoxify secondary plant compounds mediating the nutritional association between leaf-cutting ants and fungus-garden symbionts (De Fine Licht et al. 2013).

In this work, two laccases from L. gongylophorus were identified; one of them was isolated, purified, biochemically and kinetically characterized, and identified by mass spectrometry. This laccase was a yellow laccase lacking absorbance at $600 \mathrm{~nm}$ and oxidizing non-phenolic substrate in the absence of exogenous mediators. To our knowledge, no three-dimensional structure for a yellow laccase is known. Next, we built a structural model for this laccase based on homology modeling, which allowed us to analyze the catalytic site, including the amino acids that can be involved in the catalysis.

\section{Results and discussion \\ Laccases production}

The production of extracellular laccases by $L$. gongylophorus was monitored by assaying for activity in the culture medium with the method of ABTS every $48 \mathrm{~h}$ for 15 days. No significant difference in activity measured in the two culture media, with and without veratryl alcohol, was observed, which indicates that the laccase activity is not induced by the presence of the alcohol. However, we kept the veratryl alcohol in the culture medium due to its ability to inhibit protease activity (Meza et al. 2007). Laccase activity in the extracellular medium using veratryl alcohol was measured over 15 days; we observed a growth curve up to a maximum activity on the 11th day. The production of fungal laccases depends on the species and strain of the fungi and frequently occurs in 5- and 14-day-old cultures (Elisashvili and Kachlishvili 2009).

\section{Laccase purification and characterization}

After detecting laccase activity in the culture medium, the crude extract was fractionated by ionic exchange chromatography on a hydroxyapatite column. Fractions with laccase activity were pooled, dialyzed and applied onto a size-exclusion column. Fractions with laccase activity eluted from the column were pooled and concentrated. The purified laccase, here called Lac1Lg, presents an apparent molecular weight of about $66 \mathrm{kDa}$ as analyzed in SDS-PAGE (Fig. 1) and the sample purity was estimated in about $67 \%$ by the Image Lab ${ }^{\mathrm{TM}}$ Software (BioRad).

Compared with standard protein applied onto the superose 12 column, the Lac1Lg showed to be a monomeric enzyme. Most fungal laccases are monomeric proteins, but several laccases have been described as exhibiting a dimeric or trimeric structure (Baldrian 2006) and even tetrameric laccase has been reported (Thurston 1994).

The fraction containing Lac1Lg purified from superose 12 column was analyzed with zymography demonstrating laccase activity. Table 1 summarizes the yield of the enzyme in the purification procedure using syringaldazine substrate.

Here we have observed that Lac1Lg presents a light yellow color and also has no significant absorbance at $600 \mathrm{~nm}$. To better understand the characteristics of Lac1Lg, we performed a reaction with a non-phenolic 


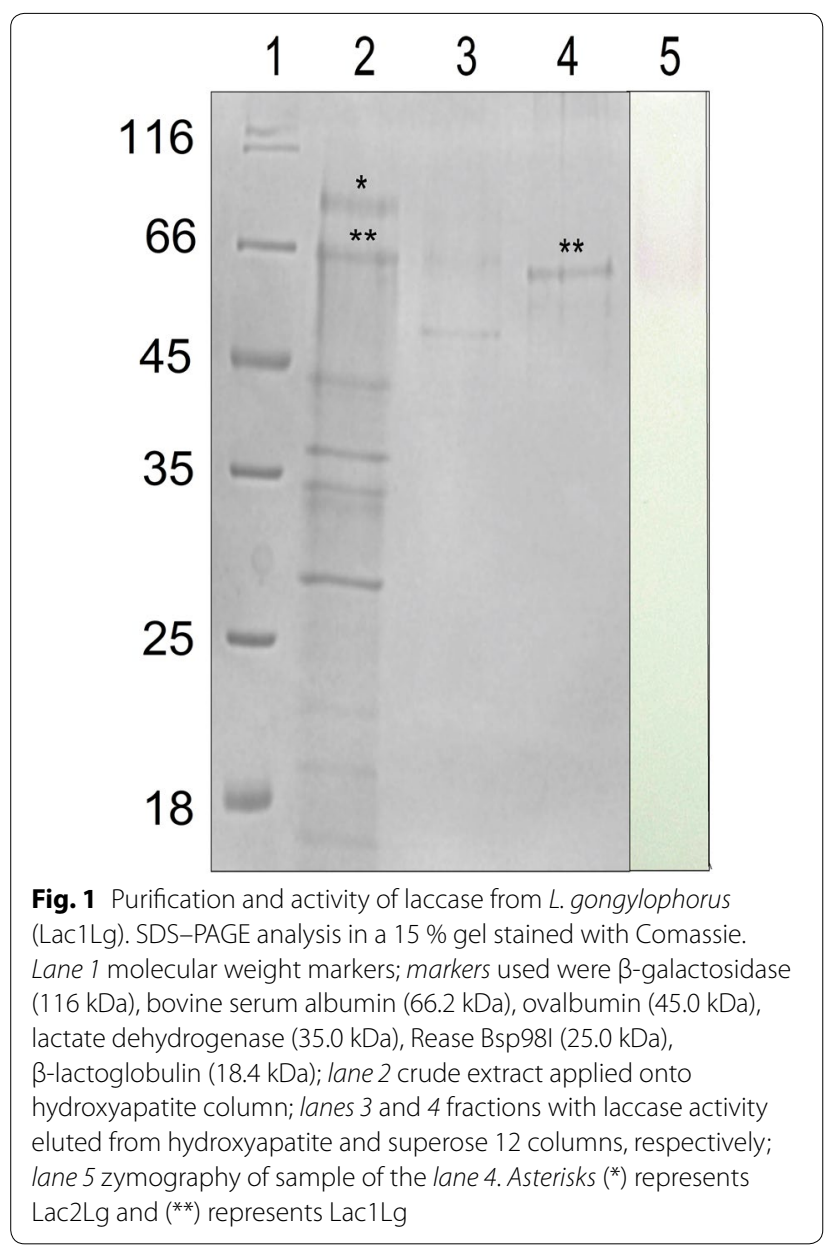

substrate (anthracene) and Lac1Lg enzyme in both the presence and the absence of ABTS, a well-known exogenous mediator. In both reactions, we detected, through mass spectrometry, the oxidation of the anthracene producing anthraquinone. Our results show that Lac1 Lg is a yellow laccase and that it does not need chemical mediators to catalyze reactions with non-phenolic substrates, which is an excellent characteristic for its use in biotechnological processes.

\section{Effect of $\mathrm{pH}$ and temperature on laccase activity and stability}

The purified Lac1Lg had its activity studied using syringaldazine and ABTS as substrates at different $\mathrm{pH}$. The maximum activity observed for Lac1Lg was at $\mathrm{pH} 6.0$ and $\mathrm{pH}$ 3.0, for syringaldazine and ABTS, respectively (Fig. 2a). The optimum $\mathrm{pH}$ values found for $\mathrm{Lac} 1 \mathrm{Lg}$ are in agreement with the literature, which describes the $\mathrm{pH}$ optima of laccases as highly dependent on the substrate. For phenols, the fungal laccases often present an optimal $\mathrm{pH}$ that can range from 3 to 7; for non-phenolic substrates, the optimal $\mathrm{pH}$ is $<4$ (Madhavi and Lele 2009). Recent studies showed two yellow laccases from the basidiomycete fungus Stropharia aeruginosa with optimum $\mathrm{pH}$ values of 4.0 and 3.0 for syringaldazine and ABTS, respectively (Daroch et al. 2014). Yellow laccases from Trametes hirsula and Aspergillus niger showed maximum activity at $\mathrm{pH} 2.4$ and $\mathrm{pH} 2.2$ for ABTS, respectively (Haibo et al. 2009; Tamayo-Ramos et al. 2012). Yellow laccase from Pleurotus ostreatus D1 showed optimum $\mathrm{pH}$ values of 7.0 and 4.0 for syringaldazine and ABTS, respectively (Pozdnyakova et al. 2006). For ABTS substrate a yellow laccase isolated from Lentinus squarrosulus presented maximum activity at $\mathrm{pH} 4.5$ (Mukhopadhyay and Banerjee 2014).

To study the interference of temperature in laccase activity of Lac1Lg, we have analyzed the reaction at different temperature values using the buffer with an optimal $\mathrm{pH}$ value. Using syringaldazine, Lac1Lg presents activity at an optimum temperature of $30{ }^{\circ} \mathrm{C}$ (Fig. 2b) and using ABTS, Lac1Lg presents the highest activity at $50{ }^{\circ} \mathrm{C}$ (Fig. 2b). The interference of temperature in laccase activity varies greatly from one strain to another, and optimum temperature values have been found for fungal laccases spanning a range of $25-80{ }^{\circ} \mathrm{C}$, with most enzymes having maximum activity at $50-70^{\circ} \mathrm{C}$ (Madhavi and Lele 2009). For example, the yellow laccase isolated from Lentinus squarrosulus presented optimum temperature at $40{ }^{\circ} \mathrm{C}$ with ABTS (Mukhopadhyay and Banerjee 2014) and the yellow laccase from Sclerotinia sclerotiorum had optimal activity within the range of $60-70{ }^{\circ} \mathrm{C}$ with the same substrate (Mot et al. 2012).

The thermal stability of Lac1 Lg was verified by incubating the enzyme in the optimal $\mathrm{pH}$ optimum at different temperatures and after the incubation period, syringaldazine was added and the activity was measured. Lac1Lg retained about 35 and $17 \%$ activity after being incubated for $1 \mathrm{~h}$ at 30 and $40{ }^{\circ} \mathrm{C}$, respectively. At $50{ }^{\circ} \mathrm{C},<10 \%$ of the enzyme activity was retained after $15 \mathrm{~min}$ of incubation.

Table 1 Recovery of activities fractions after purification of Lac1 Lg using syringaldazine substrate

\begin{tabular}{lclccc}
\hline & Protein concentration $\left(\boldsymbol{\mu} \mathbf{~ m L}^{-\mathbf{1}}\right)$ & Total activity $(\mathbf{m U})$ & Specific Activity $\left(\mathbf{m U ~}_{\mathbf{~ m}} \mathbf{- 1}^{\mathbf{1}}\right)$ & Recovery (\%) & Purification fold \\
\hline Crude extract & 300 & 0.4 & 275 & 100 & 1 \\
Hydroxyapatite & 25 & 0.1 & 907 & 8.3 & 3.3 \\
Superose 12 & 1 & 0.06 & 5716 & 0.3 & 20.8 \\
\hline
\end{tabular}



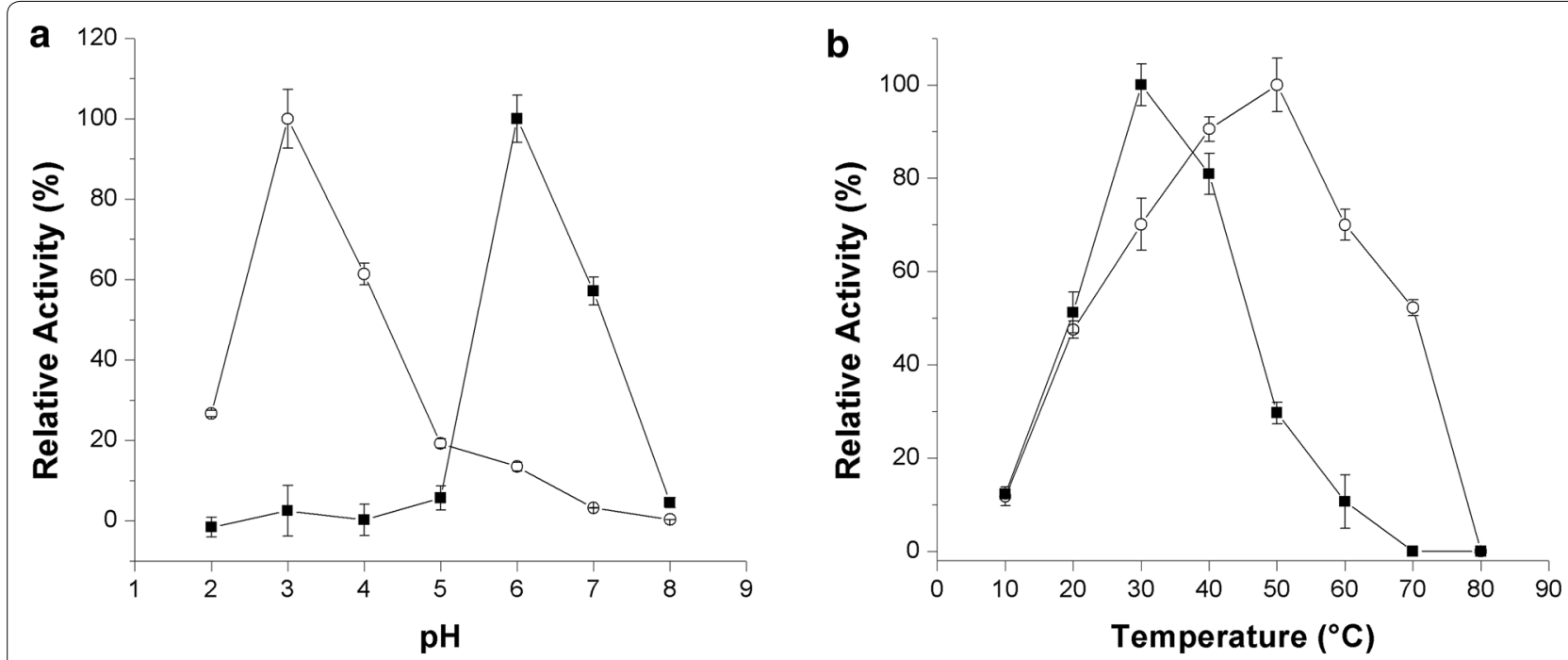

Fig. 2 Analysis of the influence of $\mathrm{pH}$ (a) and temperature (b) on Lac1 Lg using syringaldazine (filled square) and ABTS (unfilled circle) substrates. Assay conditions: Mcllvaine buffer for $\mathrm{pH}$ 2.0-8.0

\section{The effect of some substances in the activity of laccase}

Table 2 shows the influence of some substances in the activity of Lac1Lg. The laccase activity is dependent upon the presence of copper ions; the addition of EDTA, which is a chelating agent, was expected to eliminate activity. Using EDTA $5 \mathrm{mM}$ the Lac1Lg residual activity was only about $28 \%$ and it was almost abolished with EDTA $10 \mathrm{mM}$. The presence of the SDS detergent almost completely inhibited the activity of Lac1Lg, indicating that this substance negatively changes the structure of the enzyme; the same occurs for laccase produced by the hyphomycete Chalara (syn. Thielaviopsis) paradoxa (Robles et al. 2002). However, for many laccases, SDS does not affect enzyme activity, or even enhance the reaction at low concentration, such as the laccase produced by Fusarium solani MAS2 (Wu et al. 2010). Lac1Lg activity was almost completely inhibited by 2 - $\beta$-mercaptoethanol, which is a strong reducing agent, indicating the presence of disulfide bridges in its structure.

The literature describes how $\mathrm{Cl}^{-}$can inhibit laccase activity, and previous studies of laccases have showed $\mathrm{I}_{50}$ values of $0.05-600 \mathrm{mM}$ (Xu 1996). Therefore, laccase inhibition by halides is peculiar for each laccase. Lac1Lg had its activity decreased about 37 and $23 \%$ in the presence of $20 \mathrm{mM}$ of $\mathrm{NaCl}$ and $1 \mathrm{mM} \mathrm{NaF}$, respectively.

The activity for many laccases has no influence or is increased by the presence of $\mathrm{Cu}^{2+}$; however, as found for Lac II isolated from Trametes versicolor (Lorenzo et al. 2005), Lac1 Lg was inhibited in the presence of $20 \mathrm{mM}$ $\mathrm{Cu}^{2+}$. For other metal ions, such as $\mathrm{Cr}^{3+}, \mathrm{Fe}^{3+}, \mathrm{Ni}^{2+}$,
Table 2 Effects of various compounds on laccase activity of the purified Lac1 $\mathrm{Lg}$

\begin{tabular}{|c|c|}
\hline Compound & Residual activity (\%) \\
\hline Control & $100 \pm 2.2$ \\
\hline $\mathrm{CuSO}_{4}(2 \mathrm{mM})$ & $91.7 \pm 0.4$ \\
\hline $\mathrm{CuSO}_{4}(20 \mathrm{mM})$ & $36.6 \pm 1.1$ \\
\hline EDTA (1 mM) & $81.5 \pm 4.8$ \\
\hline EDTA (5 mM) & $28.1 \pm 2.8$ \\
\hline EDTA (10 mM) & $2.9 \pm 0.3$ \\
\hline $\mathrm{SDS}(5 \mathrm{mM})$ & $2.8 \pm 0.8$ \\
\hline 2 - $\beta$-mercaptoethanol (10 mM) & $0.1 \pm 0.2$ \\
\hline $\mathrm{NaCl}(20 \mathrm{mM})$ & $62.7 \pm 1.3$ \\
\hline $\mathrm{NaCl}(50 \mathrm{mM})$ & $31.8 \pm 1.1$ \\
\hline $\mathrm{NaF}(0.1 \mathrm{mM})$ & $80.4 \pm 2.4$ \\
\hline $\mathrm{NaF}(1 \mathrm{mM})$ & $76.6 \pm 7$ \\
\hline $\mathrm{NaF}(5 \mathrm{mM})$ & 0 \\
\hline $\mathrm{CuSO}_{4}(2 \mathrm{mM})$ & $91.7 \pm 0.4$ \\
\hline $\mathrm{CuSO}_{4}(20 \mathrm{mM})$ & $36.6 \pm 1.1$ \\
\hline $\mathrm{CrCl}_{3}(2 \mathrm{mM})$ & $88.3 \pm 4.4$ \\
\hline $\mathrm{CrCl}_{3}(20 \mathrm{mM})$ & 0 \\
\hline $\mathrm{FeCl}_{3}(2 \mathrm{mM})$ & $58.7 \pm 7.90$ \\
\hline $\mathrm{FeCl}_{3}(20 \mathrm{mM})$ & 0 \\
\hline $\mathrm{CoCl}_{2}(2 \mathrm{mM})$ & $96.4 \pm 1.9$ \\
\hline $\mathrm{CoCl}_{2}(20 \mathrm{mM})$ & $72.3 \pm 4.4$ \\
\hline $\mathrm{NiCl}_{2}(2 \mathrm{mM})$ & $94.8 \pm 0.5$ \\
\hline $\mathrm{NiCl}_{2}(20 \mathrm{mM})$ & $44.7 \pm 1.7$ \\
\hline $\mathrm{ZnCl}_{2}(2 \mathrm{mM})$ & $98.2 \pm 12.3$ \\
\hline $\mathrm{ZnCl}_{2}(20 \mathrm{mM})$ & $17.4 \pm 2.7$ \\
\hline DMSO $1 \%$ & $83.4 \pm 12.1$ \\
\hline DMSO $10 \%$ & $50.5 \pm 5.3$ \\
\hline
\end{tabular}


$\mathrm{Mn}^{2+}$ and $\mathrm{Zn}^{2+}$, Lac1Lg activity was decreased with increasing concentration of ions. $\mathrm{Co}^{2+}$ had the mildest effect on the enzyme activity and $\mathrm{Fe}^{3+}$ was the most aggressive. Lac1Lg showed considerable resistance in the presence of DMSO, which is very useful in assays of hydrophobic substrates.

\section{Kinetic parameters}

The kinetic parameters $\mathrm{Km}, \mathrm{V}_{\text {max }}$, kcat, and $\mathrm{kcat} / \mathrm{Km}$ were determined for the Lac1Lg enzyme (Table 3) under optimal conditions of $\mathrm{pH}$ and temperature utilizing syringaldazine and ABTS as substrates. Therefore, using McIlvaine buffer, the assays were carried out in $\mathrm{pH} 6.0$ and at $30{ }^{\circ} \mathrm{C}$ for syringaldazine and $\mathrm{pH} 3.0$ and at $50{ }^{\circ} \mathrm{C}$ for ABTS. The lower Km value for Lac1Lg was with syringaldazine, which indicates a higher affinity for this substrate than for ABTS.

Lac1Lg presents $\mathrm{kcat} / \mathrm{Km}$ almost threefold higher for syringaldazine than for ABTS, showing a higher catalytic efficiency of Lac1Lg for syringaldazine.

Despite other yellow laccases that present $\mathrm{Km}$ values for oxidation of syringaldazine and ABTS lower than that obtained for Lac1Lg (Leontievsky et al. 1997), Pozdnyakova et al. (2006) described a yellow laccase from the fungus Pleurotus ostreatus with $\mathrm{Km}$ values close to Lac1Lg (8.7 $\mu \mathrm{M}$ for syringaldazine and $110 \mu \mathrm{M}$ for ABTS) and Mukhopadhyay and Banerjee (2014) described a yellow

Table 3 Michaelis-Menten kinetic constants of Lac1 Lg

\begin{tabular}{lclcl}
\hline Substrate & $\mathrm{Km}(\boldsymbol{\mu M})$ & $\begin{array}{l}\mathbf{V}_{\max } \\
\left(\boldsymbol{\mu} \mathbf{M} \mathbf{m i n}^{-\mathbf{1}}\right)\end{array}$ & $\begin{array}{l}\text { kcat } \\
\left(\mathbf{s}^{-\mathbf{1}}\right)\end{array}$ & $\begin{array}{l}\mathbf{k c a t} / \mathbf{K m} \\
\left(\mathbf{s}^{-\mathbf{1}} \boldsymbol{\mu} \mathbf{M}^{-\mathbf{1}}\right)\end{array}$ \\
\hline ABTS & 131.9 & 3.02 & 110.7 & 0.84 \\
Syringaldazine & 5.1 & 0.16 & 11.7 & 2.3 \\
\hline
\end{tabular}

laccase with $\mathrm{Km}$ and $\mathrm{V}_{\max }$ of $71.4 \mu \mathrm{M}$ and $9.1 \mu \mathrm{M} \min ^{-1}$ for ABTS.

\section{Protein identification by MS/MS database search}

To sequentially identify the Lac1Lg, the sample was applied to a 1D SDS-PAGE gel; next, the band was excised from the gel, treated with trypsin and the peptides were analyzed by on line LC-MS nanoflow. Databases with different numbers of sequences were used to increase the protein identification confidence. By searching the nucleotide and protein databases, we identified a laccase sequence (accession number NCBI 409151740) in the published sequence of L. gongylophorus strain Ae322 so-called LgLcc6 (De Fine Licht et al. 2013). The analysis showed 13 peptides with about $27 \%$ of sequence coverage (Table 4). The Lac1Lg (corresponding to LgLcc6) sequence is shown in Fig. 3 and the peptides are in bold in the sequence. This figure shows also a sequential alignment of Lca1Lg and a yellow laccase from Stropharia aeruginosa (discussed below).

The LgLcc6 calculated molecular weight is $57,070 \mathrm{Da}$ and the Lac1Lg was observed in SDS-PAGE with about $66,000 \mathrm{Da}$. This difference in the molecular weight may be due to glycosylation, which is quite common in laccases (Hakulinen et al. 2002) and often assigned to be responsible for the thermal stability, proteolytic susceptibility, copper retention (Christensen and Kepp 2013). Laccases have been described with typically 3-10 glycosylation sites, predicted from their amino acid sequence (Rodgers et al. 2010 that represents 10 and $25 \%$, but laccases with $65-80 \%$ of saccharides have been described (Gianfreda et al. 1999). Prediction of glycosylation sites for Lac1Lg shows potential $O$-Linked and $N$-Linked glycosylated sites. Furthermore, the enzyme sample was bound in Concanavalin A (Con A) Sepharose affinity resin and eluted with $\alpha$-D-mannopyranoside (data not shown).

Table 4 Peptide coverage sequences of first hit to enzyme identified in gel band

\begin{tabular}{|c|c|c|c|c|}
\hline Search & Accession number & $\begin{array}{l}\text { Identified protein name } \\
\text { (organism) }\end{array}$ & Sequence coverage (\%) & Peptide coverage sequences \\
\hline $\begin{array}{l}\text { Leucoagaricus_NCBI_ } \\
\text { sequest }\end{array}$ & 409151740 & Laccase (L.gongylophorus) & 27.34 & $\begin{array}{l}\text { YSAVLNANQPVDNYWIR } \\
\text { YKGAPVADPTTSQQTQNDK } \\
\text { VNVVNQLTDSVQER } \\
\text { DTVNVGNTEGDFVSIR } \\
\text { GAPVADPTTSQQTQNDK } \\
\text { LLETDLHPLNHPVAPGR } \\
\text { TNLAVVNVQK } \\
\text { FNFMNPVQR } \\
\text { GSFLVER } \\
\text { VQLFAGQR } \\
\text { GALIVYDK } \\
\text { GTSVHWHGILQK } \\
\text { GALIVYDKNDPHK }\end{array}$ \\
\hline
\end{tabular}


of a blue laccase from the fungus Trametes versicolor (TvL enzyme), which has approximately $55 \%$ identity to $\mathrm{Lac} 1 \mathrm{Lg}$, was used as a template molecule. Figure $4 \mathrm{a}$ shows the general view of the superposition of the threedimensional structure of TvL (green) and the model of Lac1Lg (blue). The model presents a good fit with the structure (RMSD of $1.14 \AA$ as calculated with SuperPose web server-http://wishart.biology.ualberta.ca/SuperPose/), and we observed that the different regions are mainly in the loops. TvL and Lac1Lg have five cysteine (cys) residues with two disulfide bridges (shown in orange in Fig. 4a) and one cys binding the copper type 1 (T1 site). We can also observe the cavity in the upper part of Fig. 3a where copper type 1 is found and where the substrate bind is expected (Piontek et al. 2002). Figure 4b shows, in more detail, the copper type 1 , along with the two histidines and the cysteine that can bind the copper. TvL has not the fourth binder for copper type 1 (because methionine was replaced by Phe, represented in green in Fig. 4b) and Lac1Lg has a Leu in this same position (in blue in Fig. 4b). Studies have shown that the substitution of methionine for amino acids that do not bind to copper contributes to the higher redox potential of some laccases (Piontek et al. 2002). Figure 4b shows also the T2/ T3 site with the three copper ions, and we can observe the eight histidine residues that are expected to bind the copper types 2, 3 and 4 .
The superposition of the molecular model and the structure suggested that $\mathrm{TvL}$ (a blue laccase) and Lac1Lg (a yellow laccase) are probably structurally conserved, as observed in the blue laccases. This study showed also that Lac1Lg has the amino acids required for binding of the four copper ions. Sequence alignment (Fig. 3) between Lac1Lg and Yel1p (GenBank: AFE48785.1), a yellow laccase from the basidiomycete fungus Stropharia aeruginosa (Daroch et al. 2014) showed that they share $50 \%$ amino acid identity. We can identify the two histidines and one cysteine that could bind to type 1 copper (in blue in Fig. 4b); replacing the axial methionine is a leucine (underlined in Fig. 3). The eight histidines that bind to copper ions of the T2/T3 site were identified in the Lac1Lg sequence (in yellow in Fig. 3). Recently, Daroch et al. (2014) analyzed several sequences of blue and yellow laccases and did not identify any amino acid motifs that could explain the differences between the yellow and blue laccases. The results presented here indicated that the overall folding of the enzymes (blue and yellow laccases) are very similar and that the active site region is also highly conserved.

\section{Identification of another laccase from L. gongylophorus}

The band shown in Fig. 2 with an apparent molecular weight greater than $66 \mathrm{kDa}$ (here called Lac2Lg) was also analyzed by mass spectrometry and was identified a
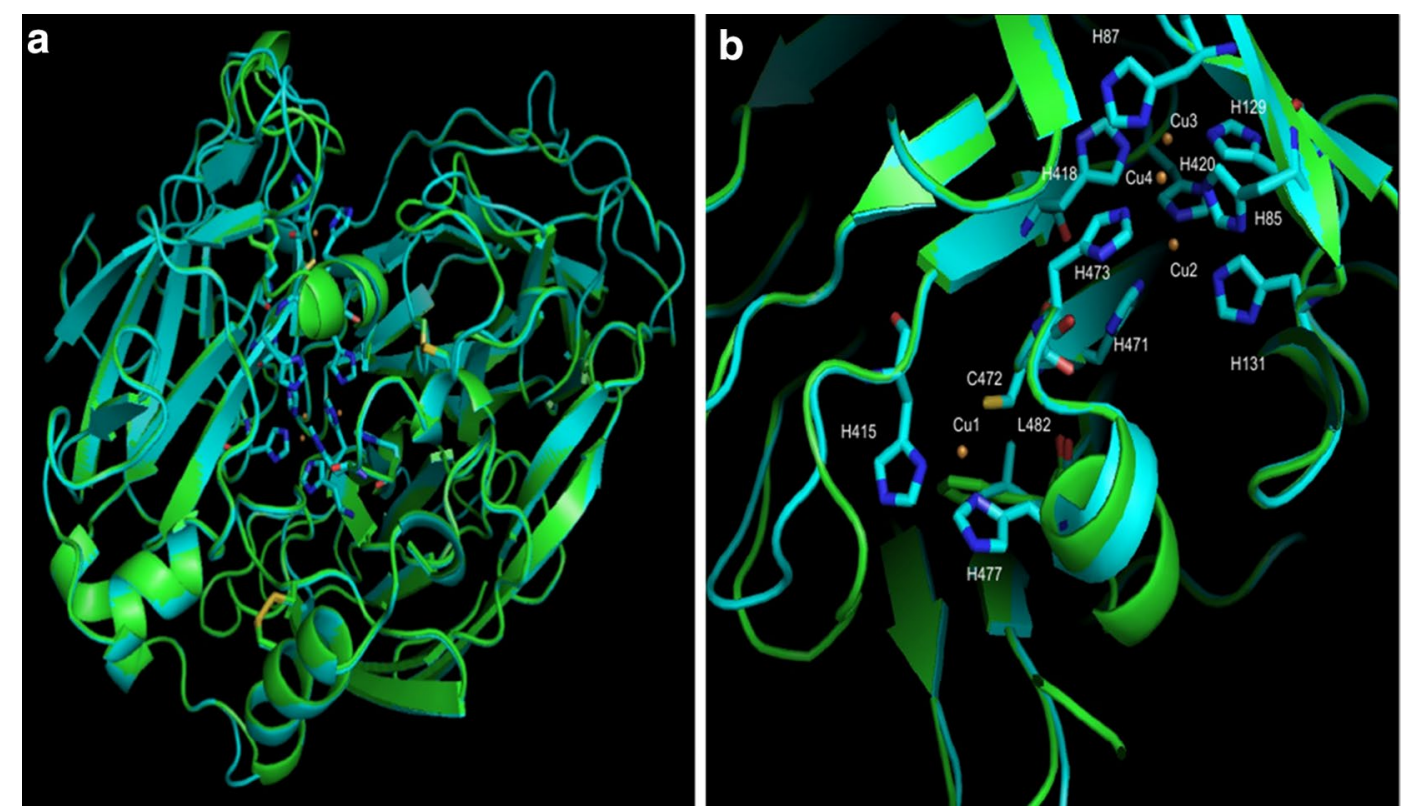

Fig. 4 Three-dimensional model of Lac1 Lg constructed by molecular modeling using SWISS-MODEL program (Biasini et al. 2014) and TVL 3D structure as template molecule (PDB 1gyc.1). Copper ions from the TVL 3D structure are draw as orange spheres. a General view of the model and the structure superposition. In blue, molecular model for Lac1 Lg and in green the 3D structure for TVL. b Copper type-1 region (T1 site) and copper T2/ T3 sites. Only His from Lac1 Lg model are showed in the T2/T3 sites 
laccase sequence (AFV15785.1) called LgLcc1, with $12 \%$ of sequence coverage. De Fine Licht et al. (2013) developed an interesting study on the laccase activity in the fungus garden of the Acromyrmex echinatior cutting ant. The authors identified nine laccase genes in L. gongylophorus (called LgLcc1-LgLcc9) and, by analysis of gene expression, detected that LgLcc1 is the most expressed gene. They suggested the function of detoxification of secondary plant compounds for laccases from L. gongylophorus. They also showed that heterologous LgLacc1 expressed in yeast showed laccase activity.

In summary, we have identified two laccases from L. gongylophorus whose genes were annotated in the genome of the fungus; one of them was characterized as a yellow laccase.

\section{Conclusions}

We have identified, in fungal culture conditions described, two laccases produced by L. gongylophorus. Lac1Lg and Lac2Lg were identified by mass spectrometry. Lac1 Lg had optimal temperature and $\mathrm{pH}$, as well as kinetic parameters, determined using both ABTS and syringaldazine substrates. Lac1Lg does not absorb at $600 \mathrm{~nm}$ and is able to oxidize non-phenolic substrates in the absence of exogenous mediators, allowing us to classify it with the so-called yellow laccases. Sequences alignment between blue and yellow laccases have shown amino acids conserved in both classes of laccases and here we have shown that these amino acids are in a favorable position for binding the copper ions.

\section{Methods}

\section{Strain and reagents}

2,2'-Azino-bis(3-ethylbenzothiazoline-6-sulfonic acid) diammonium salt (ABTS), syringaldazine and liver bovine catalase were purchased from Sigma Chemical Co., St. Louis. All other chemicals were of analytical grade. L. gongylophorus strain FF-2006 was isolated from a lab nest of Atta sexdens rubropilosa and was maintained in $2 \%$ malt extract, $0.5 \%$ bacteriological peptone, $0.2 \%$ yeast extract, and $2 \%$ agar.

\section{Enzymatic assay}

Enzymatic activity was determined by oxidation of ABTS (Wolfenden and Wilson 1982), a general substrate for some oxidases and by oxidation of syringaldazine, a specific substrate for laccase (Harkin et al. 1974). The mixture reaction for ABTS assay contained $0.5 \mathrm{mM}$ ABTS, $20 \mathrm{mM}$ sodium acetate buffer ( $\mathrm{pH} 5.0$ ), suitable amount of culture medium and $1 \mathrm{U}$ of catalase in a total volume of $0.5 \mathrm{~mL}$. Catalase was added to remove any residual $\mathrm{H}_{2} \mathrm{O}_{2}$. This reaction was incubated for $10 \mathrm{~min}$ at room temperature. Oxidation of ABTS was spectrophotometrically monitored at $420 \mathrm{~nm}$ using the extinction coefficient of oxidized ABTS of $36,000 \mathrm{M}^{-1} \mathrm{~cm}^{-1}$.

The mixture reaction for syringaldazine assay contained $10 \mu \mathrm{M}$ syringaldazine, $20 \mathrm{mM}$ sodium acetate buffer ( $\mathrm{pH}$ 6.0), $10 \mu \mathrm{L}$ of enzymatic solution in a total volume of $0.5 \mathrm{~mL}$. Oxidation of syringaldazine was measured at $525 \mathrm{~nm}$ with an extinction coefficient of $65,000 \mathrm{M}^{-1} \mathrm{~cm}^{-1}$. All assays were performed in triplicate.

One unit of laccase activity was defined as the amount of enzyme needed to oxidize $1 \mu \mathrm{mol}$ of substrate per minute.

\section{Laccases production}

To produce laccases, the mycelium of approximately $5 \mathrm{~cm}$ disks from 60-day-old cultures cultivated on solid medium was transferred to a $500 \mathrm{~mL}$ Erlenmeyer flask with $100 \mathrm{~mL}$ of modified Tien and Kirk (1988) medium (without dimethyl succinate). This inoculum was kept at room temperature $\left(25^{\circ} \mathrm{C}\right)$ without shaking for 15 days. To determine the best medium for express laccases, this experiment was also realized in this culture medium in the absence of veratryl alcohol.

To determine the optimal time of culture, aliquots of $0.5 \mathrm{~mL}$ were collected every $48 \mathrm{~h}$ for monitoring enzymatic activity by oxidation of ABTS. After determining the optimum time of cultivation to produce laccases, the culture medium was filtered through a $0.22 \mu \mathrm{m}$ membrane and then concentrated by lyophilization, re-suspended in water (in $10 \%$ of initial volume) and stored at $-20^{\circ} \mathrm{C}$. This filtered medium was called enzymatic extract.

\section{Laccase purification}

Enzymatic extract $(10 \mathrm{~mL})$ was dialyzed against $10 \mathrm{mM}$ sodium phosphate $\mathrm{pH} 5.8$ plus $0.2 \mathrm{mM} \mathrm{CaCl}_{2}$ (buffer A) for $12 \mathrm{~h}$, and was applied to an ionic exchange chromatography on a hydroxyapatite column $(1.5 \mathrm{~cm} \times 12 \mathrm{~cm}$, CHTTM Ceramic hydroxyapatite type I-Bio-Rad), previously equilibrated with buffer $\mathrm{A}$ in an AKTA-FPLC ${ }^{\mathrm{TM}}$ system (GE Healthcare Sciences). Elution was carried out using buffer $\mathrm{B}$ (400 mM sodium phosphate $\mathrm{pH} 5.8$ plus $0.0075 \mathrm{mM} \mathrm{CaCl}_{2}$ ) in a $30-\mathrm{cv}$ (column volume) linear gradient $\left(0-100 \%\right.$ of buffer B) at a flow rate of $1.0 \mathrm{~mL} \mathrm{~min}^{-1}$, and the eluted fractions were tested for laccase activity using syringaldazine as substrate. Fractions with laccase activity were pooled, dialyzed against buffer C $(50 \mathrm{mM}$ sodium phosphate $\mathrm{pH} 7.0)$ and concentrated $(10 \times)$ using ultrafiltration system (Amicon Ultra-15 Millipore). This sample was purified onto a size-exclusion chromatography on a superose $1210 / 300$ GL column (GE Healthcare Life Sciences) previously equilibrated with buffer $C$ that was supplemented with $150 \mathrm{mM} \mathrm{NaCl}$. The isocratic elution was performed with the same buffer at a flow rate of $0.3 \mathrm{~mL} \mathrm{~min}^{-1}$. 
All purification steps were performed at $20^{\circ} \mathrm{C}$ and were followed by enzymatic assays and by sodium dodecyl sulfate polyacrylamide gel electrophoresis (SDS-PAGE).

\section{UV-vis absorbance spectra}

As a part of the characterization of the physicochemical properties of the purified laccase, its absorbance spectrum from 200 to $800 \mathrm{~nm}$ was obtained in a UV-vis Beckman Coulter spectrophotometer.

\section{Zymography analysis}

For rapid detection of laccase activity, we utilized zymography technique with sodium dodecyl sulfate-polyacrylamide gel electrophoresis (SDS-PAGE) (Gonçalves and Steiner 1996). The samples loaded into the gel were not boiled and, after running, the polyacrylamide gel was renatured by incubation in a $50 \mathrm{mM}$ sodium acetate buffer $\mathrm{pH}$ 6.0, for $1 \mathrm{~h}$ (4 washes of $15 \mathrm{~min}$ ) at room temperature. Then, the activity was revealed with a solution of $10 \mu \mathrm{M}$ syringaldazine in the same buffer.

\section{Concentration and molecular weight determination}

Protein concentration was determined using Coomassie Brilliant Blue G250 according to the Bradford method using the Bio-Rad protein assay kit (Bio-Rad Laboratories, Richmond, CA) and bovine serum albumin (BSA) as standard.

Molecular weight of the purified enzyme was estimated by both SDS-PAGE and gel-filtration on a column of superose 12 calibrated by elution of standard protein BSA.

\section{Determination of optimum temperature and $\mathrm{pH}$}

To evaluate the $\mathrm{pH}$ and temperature effects on enzyme activity, the assays were developed using syringaldazine $(10 \mu \mathrm{M})$ and ABTS $(1 \mathrm{mM})$ as substrates and the concentration of Lac1Lg was 0.02 and $0.03 \mu \mathrm{g} \mathrm{mL} \mathrm{L}^{-1}$, respectively.

To evaluate the $\mathrm{pH}$ interference the assays were performed in Mcllvaine buffer at a $\mathrm{pH}$ of 2.0-8.0. To evaluate the influence of temperature on enzyme activity, the enzymatic assays were performed in the optimum $\mathrm{pH}$ buffer in different incubation temperatures $\left(10-70{ }^{\circ} \mathrm{C}\right)$.

\section{Thermal stability}

Thermal stability was verified by incubating the enzyme at optimal $\mathrm{pH}$ buffer in different temperatures $\left(30-70{ }^{\circ} \mathrm{C}\right)$ for a period of $15 \mathrm{~min}$ to $2 \mathrm{~h}$. After the incubation period, the syringaldazine substrate was added to measure enzyme activity.

\section{Kinetic characterization}

The kinetic parameters were determined for purified laccase at the optimal $\mathrm{pH}$ and temperature by measuring the initial reaction velocity and varying the substrate concentration from 0.5 to $20 \mu \mathrm{M}$ for syringaldazine and from 0.1 to $2 \mathrm{mM}$ for ABTS. The experiments were performed in triplicate, and the Michaelis-Menten constant $(\mathrm{Km})$ and maximum reaction $\left(\mathrm{V}_{\max }\right)$ values were calculated with GraphPad Prism 5.0 software.

\section{Interference of some substances in the laccase activity}

The effects of the presence of some substances on the enzyme activity were determined by incubating the enzyme with the substance for $10 \mathrm{~min}$ at optimal $\mathrm{pH}$ and temperature before performing the assay activity. Activity was measured using syringaldazine as substrate and compared with the enzyme activity as measured in the absence of substances (control).

\section{Mass spectrometry analysis}

The mass spectrometry analysis of the isolated laccase (Lac1 Lg) was carried out in gel-tryptic digestion. Sample was applied in polyacrylamide gel electrophoresis (SDSPAGE) and the protein bands excised from the gel were tryptically cleaved according to the method published by Shevchenko et al. (1996). Before LC-MS/MS analysis, samples were desalted using ZipTips ${ }^{\circledR}$ and kept at $-20{ }^{\circ} \mathrm{C}$ until the LC-MS/MS analysis.

\section{LC-MS/MS analysis}

Peptides were analyzed by online nanoflow LC-MS on an EASY-nLC II system (Thermo Scientific) connected to an LTQ-Orbitrap Velos instrument (Thermo Scientific) via a Proxeon nanoelectrospray ion source. Peptides were separated on an analytical EASY-Column $(10 \mathrm{~cm}$, ID75, $3 \mu \mathrm{m}$, C18-Thermo Scientific) previously trapped in a pre-column EASY-Column $(2 \mathrm{~cm}$, ID100, $5 \mu \mathrm{m}$, C18-Thermo Scientific). Tryptic digested peptides were separated using a 60 min linear gradient from 0 to $60 \%$ acetonitrile containing $0.1 \%$ formic acid at $300 \mathrm{~nL} \mathrm{~min}^{-1}$ flow rate.

The LTQ-Orbitrap Velos mass spectrometer was operated in positive ion mode using DDA (data-dependent acquisition) mode, in which the 20th most intense precursor ions from a full MS scan were selected for fragmentation by collision-induced dissociation (CID). Full MS scans were performed with 60,000 full-width halfmaximum (FWHM) nominal resolution settings and the $\mathrm{m} / \mathrm{z}$ range for MS scans was $400-1200$. The normalized CID collision energy was $35 \mathrm{eV}$ for a doubly charged precursor ion of $2 \mathrm{~m} / \mathrm{z}$, activation $\mathrm{Q}$ of 0.250 and activation time of $10 \mathrm{~ms}$. The minimum signal threshold was 15,000 counts and, for dynamic exclusion, it was considered 1 repeat count with a duration of $30 \mathrm{~s}$. In order to discriminate the charge state of the peptides, the charge state screening was enabled and ions with either unassigned 
charge state or a single charge were rejected. The instrument was calibrated externally according to the manufacturer's instructions.

\section{Database search}

The MS/MS spectra from each LC-MS/MS run were searched against five different databases with two different search engines and in-house Proteome Discoverer 1.4 software (Thermo, USA). MS/MS ions search criteria were used as follows: full tryptic specificity was required, two missed cleavage sites was allowed, carbamidomethylation $(\mathrm{C})$ was set as fixed modification and the oxidation $(\mathrm{M})$ was set as the variable modification, precursor ion mass tolerances were set at $10 \mathrm{ppm}$ for all MS acquired in an Orbitrap mass analyzer, and the fragment ion mass tolerance was set at $\pm 0.6 \mathrm{Da}$ for all MS2 spectra acquired.

Two analytical LC-MS/MS replicates were performed for protein excised from the gel and the raw files were considered for protein database search. The databases were downloaded by typing "Leucoagaricus" as a keyword on both NCBI and Uniprot sites, as well as "Laccase". The "Fungi_NCBI" database was used directly from the MASCOT 2.2.4 search engine with NCBInr filtered by Fungi taxonomy. The result of each run was filtered with the peptide confidence value set to high to obtain an FDR of $<1 \%$ at the peptide level. At the protein level, the minimum number of peptides is 1 for the protein, count only ranking 1 peptide and a peptide count only in the top-scored proteins were applied for all data filtration.

\section{Molecular modeling}

Protein sequence alignments were done using ClustalW2 program (McWilliam et al. 2013). The sequence of LgLcc6 (AFV15790.1) was used as an input file for the SWISSMODEL program (Biasini et al. 2014) in the construction of the three-dimensional model for the Lac1Lg enzyme. The Pymol program (The PyMOL Molecular Graphics System, Version 1.2r3pre, Schrödinger, LLC) was used to visualize the model and to superpose the model and the three-dimensional structure of $\mathrm{TvL}$, a blue laccase from the fungus Trametes versicolor (PDB 1gyc.1).

\footnotetext{
Authors' contributions

DHFS and ALMP designed the research and provided guidance; PTLI and ACM performed the purification and characterization of the enzymes; FGA and DF performed the mass spectrometry experiments; PTLI and WGB performed reaction with a non-phenolic substrate. DHFS wrote the manuscript. All authors read and approved the final manuscript.

\section{Author details}

${ }^{1}$ Departamento de Química, Universidade Federal de São Carlos, São Carlos, SP, Brazil. ${ }^{2}$ Instituto de Química de São Carlos, Universidade de São Paulo, São Carlos, Brazil.
}

\section{Acknowledgements}

This work was supported by a Grant 2011/21955-3 from the São Paulo Research Foundation (FAPESP) and CNPq (Conselho Nacional de Desenvolvimento Científico e Tecnológico, Brazil).

\section{Competing interests}

The authors declare that they have no competing interests.

Received: 21 May 2015 Accepted: 22 October 2015

Published online: 30 October 2015

\section{References}

Aylward FO, Burnum-Johnson KE, Tringe SG, Teiling C, Tremmel DM, Moeller JA, Scott JJ, Barry KW, Piehowski PD, Nicora CD, Malfatti CD, Monroe ME, Purvine SO, Goodwin LA, Smith RD, Weinstock GM, Gerardo NM (2013) Leucoagaricus gongylophorus produces diverse enzymes for the degradation of recalcitrant plant polymers in leaf-cutter ant fungus gardens. Appl Environ Microbiol 79(12):3770-3778

Baldrian P (2006) Fungal laccases- occurrence and properties. FEMS Microbiol Rev 30(2):215-242

Biasini M, Bienert S, Waterhouse A, Arnold K, Studer G, Schmidt T, Kiefer F, Cassarino TG, Bertoni M, Bordoli L, Schwede T (2014) SWISS-MODEL: modelling protein tertiary and quaternary structure using evolutionary information. Nucleic Acids Res 42(W):252-258

Bourbonnais R, Paice M (1992) Demethylation and delignification of kraft pulp by Trametes versicolor laccase in the presence of 2,2'-azinobis-(3-ethylbenzthiazoline-6-sulphonate). Appl Microbiol Biotechnol 36:823-827

Brijwani K, Rigdon A, Vadlani P (2010) Fungal laccases: production, function, and applications in food processing. Enzyme Res. doi:10.4061/2010/149748

Cherret JM (1986) The biology, pest status and control of leaf-cutting ants. Agric Zool Rev 1:1-37

Christensen NJ, Kepp KP (2013) Stability mechanisms of a thermophilic laccase probed by molecular dynamics. PLoS ONE 8(4):e80308

Daroch M, Houghton CA, Moore JK, Wilkinson MC, Carnell AJ, Bates AD, Iwanejko LA (2014) Glycosylated yellow laccases of the basidiomycete Stropharia aeruginosa. Enzyme Microb Technol 58-59:1-7

De Fine Licht HH, Schiøtt M, Rogowska-Wrzesinska A, Nygaard S, Roepstorff P, Boomsma JJ (2013) Laccase detoxification mediates the nutritional alliance between leaf-cutting ants and fungus-garden symbionts. Proc Natl Acad Sci 110(2):583-587

Ducros V, Brzozowski AM, Wilson KS, Brown SH, Østergaard P, Schneider P, Yaver DS, Pedersen AH, Davies GJ (1998) Crystal structure of the type-2 Cu depleted laccase from Coprinus cinereus at 2.2 A resolution. Nat Struct Biol 5:310-316

Elisashvili W, Kachlishvili E (2009) Physiological regulation of laccase and manganese peroxidase production by white-rot Basidiomycete. J Biotechnol 144(2):37-42

Gianfreda JMBL, Xu F, Bollag J (1999) A useful group of oxidoreductive enzymes. Biochem J 3:1-25

Gomes de Siqueira M, Bacci M Jr, Pagnocca FC, Bueno OC (1998) Metabolism of plant polysaccharides byLeucoagaricus gongylophorus, the symbiotic fungus of the leaf-cutting ant Atta sexdens L. Appl Environ Microbiol 64:4820-4822

Gonçalves MLFC, Steiner W (1996) Detection of laccase activity in polyacrylamide gels after electrophoresis under denaturing conditions. Biotechnol Tech 10(9):667-668

Haibo Z, Yinglong Z, Feng H, Peiji G, Jiachuan C (2009) Purification and characterization of a thermostable laccase with unique oxidative characteristics from Trametes hirsuta. Biotechnol Lett 31(6):837-843

Hakulinen N, Kiiskinen L, Kruus K, Saloheimo M, Paananen A, Koivula A, Rouvinen J (2002) Crystal structure of a laccase from Melonocarpus albomyces with a intact trinuclear copper site. Nat Struct Biol 9:601-605

Harkin JM, Larsen MJ, Obst JR (1974) Use of syringaldazine for detection of laccase in sporophores of wood rotting fungi. Mycologia 66(3):469-476

Huang WT, Tai R, Hseu RS, Huang CT (2011) Overexpression and characterization of a thermostable, $\mathrm{pH}$-stable and organic solvent-tolerant Ganoderma fornicatum laccase in Pichia pastoris. Process Biochem 46:1469-1474 
Leontievsky A, Myasoedova N, Pozdnyakova N, Golovleva L (1997) 'Yellow' laccase of Panus tigrinus oxidizes non-phenolic substrates without electrontransfer mediators. FEBS Lett 413(3):446-448

Lorenzo M, Moldes D, Rodríguez Couto S, Sanromán MAA (2005) Inhibition of laccase activity from Trametes versicolor by heavy metals and organic compounds. Chemosphere 60(8):1124-1128

Madhavi V, Lele SS (2009) Laaccase: properties and applications. BioResources 4(4):1694-1717

Mate DM, Garcia-Ruiz E, Camarero S, Shubin VV, Falk M, Shleev S, Ballesteros AO, Alcalde M (2013) Switching from blue to yellow: altering the spectra properties of a high redox potential laccase by directed evolution. Biocatal Biotransform 31:8-21

McWilliam H, Li W, Uludag M, Squizzato S, Park YM, Buso B, Cowley AP, Lopez R (2013) Analysis tool web services from the EMBL-EBI. Nucleic Acids Res 41(W):597-600

Meza JC, Auria R, Lomascolo A, Sigoillot JC, Casalot L (2007) Role of ethanol on growth, laccase production and protease activity in Pycnoporus cinnabarinus ss3 grown on sugarcane bagasse. Enzyme Microbial Technol 41(1-2):162-168

Moreira AC, Ferreira D, Almeida FG, Rodrigues-Filho E, Fernandes JB, Silva MFG, Vieira PC, Pagnocca FC, Souza DHF (2014) Molecular and kinetic characterization of two extracellular xylanases isolated from leucoagaricus gongylophorus. Appl Biochem Biotechnol 173(3):694-704

Mot AC, Pârvu M, Damian G, Irimie FD, Darula Z, Medzihradszky KF, Brem B, Silaghi-Dumitrescu R (2012) A "yellow" laccase with "blue" spectroscopic features, from Sclerotinia sclerotiorum. Process Biochem 47(6):968-975

Mukhopadhyay M, Banerjee R (2014) Purification and biochemical characterization of a newly produced yellow laccase from Lentinus squarrosulus MR13. 3 Biotech. doi:10.1007/s13205-014-0219-8

Piontek K, Antorini M, Choinowski T (2002) Crystal structure of a laccase from the fungus Trametes versicolor at 1.90-A resolution containing a full complement of coppers. J Biol Chem 277:37663-37669

Pozdnyakova NN, Turkovskaya OV, Yudina EN, Rodakiewicz-Nowak Y (2006) Yellow laccase from the fungus Pleurotus ostreatus D1: purification and characterization. Appl Biochem Microbiol 42(1):56-61

Riva S (2006) Laccases: blue enzymes for green chemistry. Trends Biotechnol 25(5):219-226

Robles A, Lucas R, Martínez-Cañamero M, Omar NB, Pérez R, Gálvez A (2002) Characterisation of laccase activity produced by the hyphomycete Chalara (syn. Thielaviopsis) paradoxa CH32. Enzyme Microb Technol 31(4):516-522
Rodgers CJ, Blanford CF, Giddens SR, Skamnioti P, Armstrong FA, Gurr SJ (2010) Designer laccases: a vogue for high-potential fungal enzymes? Trends Biotechnol 28(2):63-72

Shevchenko A, Wilm M, Vorm O, Mann M (1996) Mass spectrometric sequencing of proteins silver-stained polyacrylamide gels. Anal Chem 68:850-858

Silva A, Bacci M Jr, Pagnocca FC, Bueno OC, Hebling MJA (2006) Production of polysaccharidases in different carbon sources by Leucoagaricus gongylophorus Möller (Singer), the symbiotic fungus of the leaf-cutting ant Atta sexdens Linnaeus. Curr Microbiol 53:68-71

Solomon El, Sundaram UM, Machonkin TE (1996) Multicopper oxidases and oxygenases. Chem Rev 96:2563-2605

Tamayo-Ramos JA, van Berkel WJH, Graaff LH (2012) Biocatalytic potential of laccase-like multicopper oxidases from Aspergillus niger. Microb Cell Fact 11:165. doi:10.1186/1475-2859-11-165

Thurston CF (1994) The structure and function of fungal laccases. Microbiology 140:19-26

Tien M, Kirk TK (1988). In: Wood WA, Kellogg ST (eds) Methods in enzymologybiomass, part b, lignin, pectin, and chitin, vol. 161. Academic Press, San Diego, pp 238-249

Viswanath B, Rajesh B, Janardhan A, Kumar AP, Narasimha G (2014) Fungal laccases and their applications in bioremediation. Enzyme Res. doi:10.1155/2014/163242

Wolfenden RS, Wilson RL (1982) Radical-cations as reference chromogens in the kinetic studies of one-electron transfer reactions: pulse radiolysis studies of 2,2'-azinobis-(3-ethylbenzthiazoline-6-sulphonate). J Chem Soc Perkin Trans 2:805-812

Wu YR, Luo ZH, Kwok-Kei Chow R, Vrijmoed LL (2010) Purification and characterization of an extracellular laccase from the anthracene-degrading fungus Fusarium solani MAS2. Bioresour Technol 101(24):9772-9777

Wu X, Zhan X, Gan M, Zhang D, Zhang M, Zheng X, Wu Y, Li Z, He A (2013) Laccase 2 is required for sclerotization and pigmentation of Aedes albopictus eggshell. Parasitol Res 112:1929-1934

Xu F (1996) Oxidation of phenols, anilines, and benzenethiols by fungal laccases: correlation between activity and redox potentials as well as halide inhibition. Biochemistry 35:7608-7614

Xu F, Palmer AE, Yaver DS, Berka RM, Gambetta GA, Brown SH, Solomon El (1999) Targeted mutations in a Trametes villosa Laccase. Axial perturbations of the T1 copper. J Biol Chem 274(18):12372-12375

\section{Submit your manuscript to a SpringerOpen ${ }^{\odot}$ journal and benefit from:}

- Convenient online submission

- Rigorous peer review

- Immediate publication on acceptance

- Open access: articles freely available online

- High visibility within the field

- Retaining the copyright to your article

Submit your next manuscript at springeropen.com 